\title{
Communicating risk and protection: advertising discourse of young children's healthcare products and parental reception in China
}

\begin{abstract}
This paper analyses the representation and reception of the advertising of children's healthcare products on Chinese television. It engages with the concept of risk to analyse the representation of a coherent narrative of young children's health-related risks comprising messages of environment, nature, nutrition, and science. Within the narrative, interconnected risks - risks of everyday living, risks of environment pollution, risk of malnutrition - as well as a wider discourse of 'risk and protection' are constructed. This paper also analyses parents' reception of the discourse and their responses to perceived and real health risks contextualised in a neoliberal system marked by medicalised children's healthcare and 'truncated' civic rights in China. This paper argues that these institutional conditions reinforce the risk-centred narrative which invokes heightened parental uncertainties and anxieties about childrearing as part of the modern cultural experiences in China.
\end{abstract}

\section{Keywords:}

Risk, advertising, environment, nature, science, children, parents, healthcare, neoliberalism, semiotics, China

Word count: 7,970

\section{Introduction}

China's unique state-led modernisation project has garnered a great deal of academic interests, but academic research has inadequately addressed modernism in the Chinese context as a 'cultural experience' marked by uncertainty, ambiguity, doubt, risk and continual change (Barker, 2012: 185-186; Zinn, 2006). Few studies have engaged with the concept of risk to understand individuals' 'structure of feeling' about health issues in China underpinned by a range of social and cultural processes including individualisation, rationalisation and commodification (Sun, 2015; Chen, 2008; Thiers, 2003; Kohrman, 2008; Klein, 2013). This paper engages with the concept of risk to analyse the cultural representation of risk in commercial advertising, as well as the complex and dynamic processes of risk perception and management by new parents in China. It firstly outlines its theoretical approaches and introduces contextual issues - a healthcare system governed by neoliberal rationality and characterised by individualisation and self-care. The paper then discusses the methodology before it turns to the main analysis.

\section{Modernism as a cultural experience - change, uncertainty and health-related risks}

The modernisation process has had a major impact on how individuals make sense of their everyday life. Cultural studies scholars use 'modernism' to refer to the 'human cultural forms bound up with modernization (Berman quoted in Barker, 2012: 185). In this school of thought, modernism is conceived as a culturâl experience or 'structure of feeling' (Williams quoted in Barker, 2012: 185) marked by continual change, risk, and uncertainty. 
Final submitted peer reviewed manuscript accepted in European Journal of Cultural Studies (2016) by Gong, Qian., University of Leicester.

Such cultural experience is the result of changes in modern societies where traditional constraints in religion, gender, family, class, and status have been removed, and individuals have been given more choices in shaping their own biographies. Changes in these aspects have extended more freedom to individuals but also created a sense of insecurity as they face uncertainties arising from employment, health, social and family relationships (Beck, 1992; Beck and Beck-Gernsheim, 1995), and are compelled to deal with these uncertainties seen largely as individual, rather than socially-based, problems (Lupton and Tulloch, 2002: 318). ${ }^{1}$

Amongst a number of theories about modernisation, Beck's (1992) risk society thesis has been particularly influential. He proposes that late industrial societies have been moving towards 'risk society' characterised by numerous risks and a high level of public awareness of these risks. In the area of health-related environmental problem where Beck developed the risk society thesis, ${ }^{2}$ he argues that the Western and global world see increasing threats to public health posed by environmental pollution, food poisoning, and nuclear radiations, many of which are invisible, pervasive, incalculable and complex risks caused by science and technology in the early modernising stages (Beck, 1992). In the meantime, personal health has been framed as an individual responsibility, especially in societies dominated by neoliberal ideologies (Beck-Gernsheim, 2000: 124).

Beck's risk society thesis has been seminal in creating a new ground to understand late modern society through the concept of risk on the theoretical level, but critics argue that empirical analysis of individuals' risk experience and perceptions is lacking (Lupton, 1999a; Wilkinson, 2001; Lash, 1993; Lupton and Tulloch, 2002). More than twenty years after the publication of Beck's Risk Society, a great volume of literature has emerged, responding to the criticism of lacking empirical, ground-level analysis of the risk experience and perceptions of people who are affected by risk discourses. In the narrow subject of motherhood and infant health, which is in close proximity to the subject of this paper, a rich body of literature has engaged with the concept to risk, documenting tensions, contradictions and ambivalence in individual experiences caught between the expertguided neoliberal discourse of self-responsible citizen and moralised discourse of good mother (Murphy, 2000; Lee, 2008; Knaak, 2010; Lupton, 1999b). But in the Chinese context very limited academic debate has emerged, in particular in the area of health, partly because of inadequate theoretical and empirical engagement with the concept of risk. This paper therefore aims to make a modest contribution to the gap in the literature. It seeks to analyse the representations of health risks in the advertising of children's healthcare products, as well as parents' reception of the in China. This paper is informed by a socio-cultural approach to the concept of risk (Lupton, 1999a; Lupton and Tulloch,

\footnotetext{
${ }^{1}$ The 'personal freedom' experienced in the individualisation process should be understood critically. As Beck and Beck-Gernsheim (1995: 7) argue that individuals freed from traditional constraints are often subject to new constraints, for example, set by the labour market. The term of individualisation as they argue, 'covers a complex, manifold, ambiguous phenomena'.

${ }^{2}$ Beck's risk society has been criticised for its narrow focus on technical and environmental risks and the responses to them (Zinn, 2006). Recognising the limitation, this paper however follows some of Beck's main arguments about risk, environment, science and technology as these themes are central in the risk construction in the adverts of children's healthcare products.
} 
Final submitted peer reviewed manuscript accepted in European Journal of Cultural Studies (2016) by Gong, Qian., University of Leicester.

2002) and a cultural approach to health communication (Lewis and Lewis, 2015). In the following section, I outline the details of the two approaches both of which address the critique of Beck's risk concept discussed previously.

\section{Theoretical approaches and research objectives}

Lupton and others argue that empirical analysis of individuals' risk experiences and perceptions is lacking in Beck's theorisation (Lupton, 1999a: 6; Lupton and Tulloch, 2002: 322; Wilkinson, 2001: 138). In her edited volume, Lupton and exponents propose a sociocultural approach towards the concept of risk, focusing on understanding the broader social, cultural and historical contexts that give risk its meanings (Lupton, 1999a: 2). According to this approach risks can be analysed at both macro and micro levels. The macro-level analysis investigates the social conditions of risk discourse including social trends of individualisation and medicalisation; ${ }^{3}$ the micro-level analysis examines the cultural conditions of individuals' risk responses and perceptions related to 'personal biographies' and grounded in 'everyday experiences and social relationships' (Lupton, 1999a: 6; Lupton and Tulloch, 2002: 331).

To use the socio-cultural approach to analyse individual's situated health risk experiences, this paper further draws on the cultural approach to health communication proposed by Lewis and Lewis (2015) who emphasise the importance of the media and culture in understanding how we communicate messages and meanings about health. They argue that diverse media images and stories in news reporting, entertainment, advertising, social media and other media forms exert influence on people's thinking about health (Lewis and Lewis, 2015: 29), but also point out that the relationship between the media and audiences is complex because people make sense of media texts based on their 'own personal experiences, significant social groups, knowledge systems, cultural practices and beliefs' (Lewis and Lewis, 2015: 13). Essentially Lewis and Lewis's approach proposes to use perspectives of cultural studies in a health communication context. It is not surprising to see that their approach shares a central argument with audience research which maintains that media audiences actively engage with media texts and images rather than passively receive them (Ang, 1996; Morley, 1992; Silverstone and Hirsch, 1992). Lewis and Lewis (2015: 33) also argue that people interpret media texts about health issues differently based on their past experiences, pre-existing knowledge, values, beliefs and background, generating 'multiple meanings'. While such conceptualisation which approximates Hall (1997) and Morley's (1980) concepts of 'polysemy media text' and 'decoding' offers nothing new in the field of cultural studies, it does however challenge the linear, top-down and expert-led model of transmission that has dominated the field of health communication. Their approach, by conceiving health communication as a process of exchange between the audience, the media, and (less) powerful social groups involved in producing meanings of health, emphasises that audiences themselves are engaged in the meaning-making and therefore become agents of change (Lewis and Lewis, 2015: 13).

\footnotetext{
${ }^{3}$ See Lupton's (1999b) analysis of the rise of risk discourses around pregnancy in Australia.
} 
Final submitted peer reviewed manuscript accepted in European Journal of Cultural Studies (2016) by Gong, Qian., University of Leicester.

Both approaches outlined above address the critique of Beck's risk society thesis. They jointly inform this paper to locate parents' situated risk experiences in their everyday encounters with the media (advertising of children's healthcare products), and to understand the complex and dynamic processes of risk perception and management based on parents' personal experiences, knowledge systems, cultural practices and beliefs. The key questions asked in this research follow Lupton's questions about how risk logic is produced and operated in situated experiences (Lupton, 1999a: 6): What messages do the adverts convey about children's health risks and how do they convey the messages? What sources of information do parents draw on to make sense of the messages and how? Do parents adopt a rationalistic reflexive approach? Whether socio-cultural factors play a role in the ways that they understand the meanings of risk? What pre-existing knowledge, experience, beliefs, and subject positions do they draw on to make sense of the risks? After outlining the theoretical approaches and research objectives of this paper, in the next section I provide a short discussion of the social contexts of the issues of health and 'risk' in China.

\section{Health and 'risk' in China}

The current Chinese society in particular its health sector exhibits many key features of modern risk society characterised by a rise of individualisation and a healthcare system governed by neoliberal ideas and practices. From Chairman Mao's collectivist social engineering movements to the economic reform, Yan and exponents (Yan, 2010; Davis, 2000; Griffiths, 2013) have observed changing patterns of individual biographies including freedom in forming social and personal identities, creating personal wealth and choosing individualised lifestyles, all of which constitute key components of the individualisation process. ${ }^{4}$ In the health sector, the rise of individualisation is largely situated within a wider context of the commodification and privatisation of health and wellbeing. In 1978, a major reform of the Chinese healthcare system informed by neoliberal values was introduced. ${ }^{5}$ It organised the health system based on market competition and drastically reduced government funding. It was during this stage the Chinese healthcare system saw poor medical insurance coverage, hospital overtreatment, excessive use of drugs, increased costs for medical care, and deteriorating patient-doctor relationships (Li, 2011; Liu and Mills, 2002; Manning, 2011: 656; Du, 2009). Between 1980s and 1990s, the concept of healthcare has shifted from one based on public good to one based on individual responsibilities. The Chinese public have become self-care 'biocitizens' via self-medication in a top-down nationwide health promotion process led by experts (Sun, 2015: 296; Chen, 2008).

In the new neoliberal context, health is viewed as a consumption activity operated in a free market dominated by biotechnologies and international pharmaceutical companies, and the individuals view health as an equivalent to lifestyle that can be bought from 'commodified packages' ranging from multivitamins, over-the-counter medicines (OTCs), cosmetic surgery and luxury health clubs (Chen, 2001: 180). As incidents of chronic diseases in China increased significantly in the past decade (Normile and WTO cited in Daemmrich, 2013:

\footnotetext{
${ }^{4}$ It is important to note that basic civic and political rights such as freedom of speech and assembly are still limited in the individualisation process in China, see Yan 42010) and Beck and Beck- Beck-Gernsheim (2010). ${ }^{5}$ In 2006 a further reform seeking to build a universal health security system was introduced but critics argue many legacy problems from the neoliberal reform remained. See Li (2011).
} 
Final submitted peer reviewed manuscript accepted in European Journal of Cultural Studies (2016) by Gong, Qian., University of Leicester.

455), the healthcare product market also grew exceptionally. It was predicted that healthcare spending will reach $\$ 1$ trillion, 7 per cent of the estimated GDP, by 2020 (Le Deu et al. cited in Daemmrich, 2013: 448). The vitamins and dietary supplement market alone was valued to be worth of $\$ 16.4 \mathrm{bn}$ in 2014 by Euromonitor (2015). In the meantime, as the state withdraws from managing health issues on the individual level, individuals find themselves in need of affordable information, trustworthy knowledge and expert advice (Lewis et al., 2012: 550-551). Popular media as a pervasive cultural force often play an important role (Lewis and Lewis, 2015: 29). Lewis and colleagues (2012: 539) argue that as the state 'retreats' from the care of its citizens, the media step in to take a pedagogical role in giving life advice in East Asia, including China. Sun (2015: 296) further analyses how lifestyle programmes funded by commercial sources supply much health information to the Chinese public, providing health literacy education. Other forms of commercial media content, for example, adverts of healthcare products are omnipresent in peoples' everyday life in China (Huang et al., 2010), acting as a powerful cultural agent in shaping people's beliefs, desires and value system with regard to their understanding of health issues (Lewis and Lewis, 2015: 29).

\section{Methodology}

This paper uses semiotic analysis and focus groups, and draws on three sets of data: 58 infant formula TV adverts collected from Adtopic, 72 healthcare products TV adverts collected from AdmanGo, ${ }^{6}$ and six focus groups with parents whose children are under the age of four. ${ }^{7}$ The analysis of advertising images and texts based on semiotic analysis is accompanied by the analysis of focus group discussions. The mix-method approach offers the possibility to explore not only the construction of the meanings in the adverts, but also the nuanced process of meaning-making by the parents. The first set of data was collected from the search engine on Adtopic's website, using the keyword 'milk powder' ('nai fen') in 2012. After excluding duplicate adverts and milk formula adverts for adults (e.g. pregnant women and seniors) a total of 58 adverts were collected, covering a four-year period from September 2008 to September $2012 .^{8}$ The second set of data was collected from AdmanGo.com in 2014, an online database that provides advertising monitoring in China. I conducted a 'category' search on the online database using the following criteria:

\footnotetext{
${ }^{6}$ The promotion of healthcare products in China is significantly dominated by TV advertising $-96.61 \%$ of the total advertising expenditure on healthcare products was taken up by TV advertising in 2009 (Huang et al., 2010). This suggests that TV advertising of healthcare products should be investigated as a primary site of meaning construction.

${ }^{7}$ While there is no agreed definition of healthcare products, they are usually translated as 'baojian pin' in Chinese. Most parents in the focus groups tend to use the term 'baojian pin' to refer to infant formula products, dietary supplements (fish/liver oil, multivitamin and mineral supplements, probiotics drinks) and other tonic drinks or compounds made from medicinal food. The selection of the adverts of these products is based on the common understanding of 'baojian pin' by the parents. Focus group participants comprise 34 mothers and 2 fathers, indicating parenting is still a gendered labour in China. Parents come from middle-class and above, middle-class and middle class and below backgrounds. Focus group data represent certain socioeconomic diversities but have a middle-class focus.

${ }^{8}$ In September 2008 a food scare of adulterated baby formula took place in China, killing six babies and hospitalised 300,000 . The food scare and its associated food safety risks had far-reaching impact on the risk perception of the Chinese public. Based on this September 2008 was used as the starting point of data collection.
} 
Final submitted peer reviewed manuscript accepted in European Journal of Cultural Studies (2016) by Gong, Qian., University of Leicester.

'TV' adverts, 'Pharmaceuticals and healthcare' adverts, and 'children products' from September 2008 to September 2012. The search returned 465 items. After a manual search excluding duplicates and adverts of over the counter medicines, ${ }^{9}$ in total 72 adverts were retrieved and collected from the database. Adverts from both data sets are in video format and have been broadcast on regional and national TV channels in China, lasting from 5 to 30 seconds.

As previous research has established that 'protection' is a salient theme in the adverts of children's healthcare products such as infant formula (Authors), all adverts from both data sets were viewed repeatedly to identify the ones that convey the message of 'protection'. It was found that a significant number of adverts (26) had constructed the narrative of 'protection' with an underlying message of 'risk'. These adverts were further investigated with semiotic analysis, a method developed from Saussure's (1983) semiology and now commonly used in media and cultural analysis to study the meaning of signs and symbols. A central concept in Saussure semiotics is sign, comprising two key components - 'signifier' and 'signified' ${ }^{10}$ - with which we make sense of our world including the communication system. However, because the relationship between the signifier and signified is arbitrary (Saussure, 1983), semioticians argue that one must interpret signs with 'code' - a set of practices familiar to users of the medium operating within a broad cultural framework' (Berger, 2012: 32; Chandler, 2007: 148) - as codes provide a framework within which signs make sense. Following this conceptualisation, I firstly compared and contrasted the adverts and identified important and recurrent textual signs (written words and voice-overs) and visual signs (shapes, images and colours). Then I examine the signification by analysing word choices, the selection of visual objects and colours, and the composition of the signifiers. I then engage with 'interpretive codes' - socially shared perceptions, assumptions and views shaped by parents' individual experiences, pre-existing knowledge, values, beliefs and background - to analyse how the signifiers generate a range of meanings about health and risks.

The third set of data was based on six focus groups with parents living in Chengdu conducted between 2014-2015, with each lasting between 60 and 90 minutes. ${ }^{11}$ The data were used to explore how parents decoded the (sometimes ambiguous) meanings of the signs (texts and images in the adverts). Groups were internally homogeneous, consisting of six friends or acquaintances from similar socio-economic backgrounds (e.g. mothers from middle-class background, parents from middle-class and below background, etc.). Openended questions were asked about parents' understanding of health-related risks for their children, including the ones portrayed in the adverts (shown on mobile devices to parents as prompts), their responses to the risks and sources of information supporting their responses. These questions allowed parents to explore their personal experiences, pre-

\footnotetext{
${ }^{9}$ Adverts of over the counter medicines were excluded because focus groups discussions suggest that parental selection of medicine tends to closely follow the guidance of medical professionals, and that adverts have little impact on their purchase intention.

10 'Signifier' refers to the form (sound-image) that the sign takes whereas 'signified' refers to the concept to which the sign refer (Berger, 2012: 6).

${ }^{11}$ All focus groups were audio recorded and transcribed. The transcripts were reviewed repeated by the author and analysed thematically. The project is funded by.... It received ethical approval from (information withheld for peer review) in August 2014. All names of the participants have been anonymised.
} 
Final submitted peer reviewed manuscript accepted in European Journal of Cultural Studies (2016) by Gong, Qian., University of Leicester.

existing knowledge, beliefs, and subject positions, as well as other socio-economic and political issues, in order to explain the ways in which they make sense of the messages in the adverts.

\section{'Dangerous world' and environmental risks}

Previous research (Authors) has identified popular themes in the adverts of infant formula including science and nature in the wake of the baby milk scandal in China in 2008, and the ways in which advertisers used these themes to mediate the message about food safety. While this is a prominent theme of the adverts of infant formula, in this paper I argue that there is an underlying narrative of 'risk and protection' in the adverts of children's healthcare products more generally. In the following analysis, I focus on the construction of the narrative in several adverts and the reception of the narrative by parents.

A key message constructed as the pretext of the 'risk and protection' discourse is a 'dangerous world' and various environmental risks associate to it. These adverts often suggest that children's everyday environment is 'dangerous', and children are vulnerable little human beings who are susceptible to threats from the outside world. Healthcare product manufacturers draw on parental anxieties about children's vulnerability to promote the immunity- boosting function of their products which is often represented by signifiers of protection such as shield, umbrella, gloves, kangaroo pouch and angel's wrapping wings. Danone's Dumex is a leading international infant formula brand trading China. One of its product lines named 'Golden Shield' ('Jin Dun') has been marketed for the protective function, featuring its unique 'immunofotis' which contains probiotics for boosting young children's immune system. In Dumex's advert, the main character - a toddler - is playing in an outdoor environment in various weather conditions, while other children are protected by umbrellas and thick parkas or stay indoors. The advert shows that when the toddler touches rain drops and snowflakes or jumps in muddy puddles, he is protected by a golden shield (see Figure 1, visible here in the screenshot with its golden contour). At the same time, the rainy and snowy weather turns into a good weather represented by a blue sky and bright light. The voice- over from the mother who is standing in the background says: 'I encourage my little one to experience the world...Protected by his own immune system, I'm assured ('fang xin') that he can safely discover this colourful world' (italics my emphasis). Although words such as 'danger' and 'risk' are not used here, the usual association of these words with the words 'protected', 'assured' and 'safely' in the voice-over implies the existence of the dangerous and risky situations. The mother's facial expression and body language - smiling but slightly leaning forward with her head tilted down to watch her son closely - depicts a content (because of the protection offered by immunofotis) but still a vigilant parent. The verbal message in the voice-over and the visual meaning of mother's figure therefore jointly construct a narrative about 'danger and (effective) protection'.

\section{Figure 1}

In another advert of Mentholatum's Rohto Eye Drops for children, air pollution is clearly identified as a risk factor for damaging optical health (see Figure 2). The screen is split into two sections. On the left it shows two tall industrial chimneys emitting smoke as the central 
Final submitted peer reviewed manuscript accepted in European Journal of Cultural Studies (2016) by Gong, Qian., University of Leicester.

visual element. They evoke an association with industrial factories as sources of pollution. A blue sky signifying clarity and cleanness is portrayed in the background, contrasting and foregrounding the pollution caused by the smoke. On the right, it shows the face of a concerned mother who reads out the texts (also shown on the screen): 'dust and pollution damage your baby's eyes'. The mother's concerned face is shown in a close-up shot, making it more 'personal' to the audience to evoke similar anxious emotions. The direct visual juxtaposition of industrial pollution and mother's concerned face conveys a clear message: (parent's) concern about dangerous environmental pollution.

Figure 2

While most adverts portraying a 'dangerous world' locate risks and dangers in outdoor environments, some adverts however extend the location of these risks and dangers to domestic environments in which the floor, curtains, TV stand or even other people have become sources of potential health risks. In another advert of Dumex which features a little boy's birthday party, it shows several scenes whereby the mother stops the boy from picking up a spoon from the floor, wipes an apple before handing it back to him and uses a napkin to separate him and a sneezing little girl. Here dust and germs from home have become sources of health risks, which according to the advert, can be prevented by Dumex's 'immufortics' probiotics. In the next image (see Figure 3), the golden shield of the 'immufortics' is shown in the stomach area of the toddler. It 'emanates' a shining contour of the toddler, indicating its protective functions.

Figure 3

Everyday living (outdoor or indoor) environments are represented here as risky as they pose physical harms to young children. These physical risks are often implied in the construction of other adverts which extend the location of the risks to undisturbed natural environments. Nanshan (Figure 4), a leading Chinese infant formula brand also builds its storyline around 'protection' and illustrates its protective function in the shape of two wings, wrapping around a toddler holding a sippy cup of formula milk.

\section{Figure 4}

This advert suggests that the toddler needs to be protected against the threats from the natural environment as the voice-over says: 'To let your baby close to nature, you need to give her/him double protection' (italics my emphasis), even though the natural environment is favourably represented with a clear blue sky, white cloud and open green grassland, signifiers commonly used to romanticise nature. Similarly the advert for Aoyou infant formula also suggests that babies need protection (see Figure 5), as its accompanying song sings 'mummy kangaroo has a pouch. The pouch is for protecting the baby' (italics my emphasis). The natural environment in this advert is again favourably represented with a blue sky, white cloud, trees and green pasture in the background.

Figure 5

While adverse weather conditions such as rain and snow may potentially pose real health 
Final submitted peer reviewed manuscript accepted in European Journal of Cultural Studies (2016) by Gong, Qian., University of Leicester.

risks by causing a cold for instance, the favourable open natural environment represented in these adverts is hard to be linked to dangers or risks. Yet most new parents were sceptical of such environments represented in the adverts, believing that some sort of 'protection' was necessary. When asked what parents made of the message of 'dangerous environment requiring protection', many supported this view and believed that they 'need to be more careful when taking their baby outside'. Most parents thought 'protection' was necessary as natural environment was heavily polluted in urban China. When talking about outdoor environment, parents seemed to have leapt from the images of favourable natural environments depicted in many adverts to those of polluted environments (e.g. Mentholatum's Eye Drops advert). Parents pointed out that the representation of the natural environment in the adverts was 'unrealistic', 'fake' or 'impossible' when they commented on their distrust of deceptive and misleading adverts due to lax regulation in China. ${ }^{12}$ They highlighted the outdoor environment as a source of health risk, with particular reference to smog episodes that have received sustained negative news coverage in Chengdu in the past few years.

A: The smog is so scary. I had sore throat and itchy nose when Chengdu had a few smog days last year. I'm an adult; imagine what that could do to babies. B: My baby got a bad cold last winter and ended up in hospital. He had IV drops put in from his forehead. The air was horrible! It killed to me think that when he got out of the hospital, he was exposed to this air again.

Researcher: What did you do about the smog?

A: We stayed home. There was no choice. And there was nothing I could do because everywhere was the same. If the weather was foggy, or if it rained, we stayed home and kept all windows shut.

B: We'd only go out if I can see a clear sky. But you don't get many of these in Chengdu, especially in winter. (mothers from middle class and below background)

Recent negative media coverage of the smog and other environmental problems has caused great concerns among the public in China, which has evidently influenced new parents' perceptions of the environmental risks. Parents frequently refer to news, adverts and mobile applications as their sources of information about environment pollution:

C: When it's a bad day, I keep my child at home. Last winter there was news and adverts on TV, telling grandparents not to take their grandchildren outdoors when PM2.5 level was high. ${ }^{13}$ I also kept an eye on it.

R: How do you do it? Do you follow daily weather forecast on TV?

\footnotetext{
${ }^{12}$ For discussions on dishonest adverts in China see Hong J. (1994) The resurrection of advertising in China: Developments, problems, and trends. Asian Survey 34: 326-342.

${ }^{13}$ According to the US Environmental Protection Agency (2014), PM refers to particulate matter, and is the term for 'particles found in the air, including dust, dirt, soot, smoke, and liquid droplets'. PM2.5 refers to 'particles less than 10 micrometers in diameter (PM10) pose a health concern because they can be inhaled into and accumulate in the respiratory system. Particles less than 2.5 micrometers in diameter (PM2.5) are referred to as "fine" particles and are believed to pose the greatest health risks'. 'United States Environmental Protection Agency. (2014) What is PM2.5? Available at: http://www.epa.gov/pmdesignations/faq.htm\#0.
} 
Final submitted peer reviewed manuscript accepted in European Journal of Cultural Studies (2016) by Gong, Qian., University of Leicester.

C: No, I use an app on my phone. You can't really trust the official weather forecast - they won't tell you the truth which is usually quite bad.

D: Last December the air quality was particularly bad, PM 2.5 levels were off the chart.

$\mathrm{R}$ (speaking to $\mathrm{D}$ ): Do you use mobile app to monitor it too?

D: No, I don't use that but everyone talks about it and you can see the forecast on TV, newspapers, and the internet. (parents from middle class background)

It is evident from the above quotes that parents are highly risk conscious, and that parents' perception of increased environmental risks is shaped by their daily encounters with the media and their coverage of environmental pollution. Parents' background knowledge of polluted environment and their distrust of dishonest adverts form their perceptual codes. They draw on these codes to interpret the favourable portrayal of nature comprising signifiers such as blue sky and green pasture, leading them to reject such representation.

Parents' perception of increased environmental risks due to pollution is consistent with the main message in the adverts ('dangerous environment requiring protection') despite some of the adverts' favourable yet self-contradictory representations of nature. It shows that the perceptions of risk are not entirely formed on the basis of rational assessment (e.g. prompted by imageries of pollution). Rather as Zinn (2008: 439) argues, strategies such as the use of emotion for managing risks are often in-between rational and non-rational approach and are based on the use of prior knowledge and experience. The above quotes from parents show that prior experience of smog and emotion (intensified fear towards baby's suffering - IV drops) have perhaps worked on a subconscious level to heighten parents' risk perception. For parents who draw on their perceptual codes containing background knowledge of environment pollution and assumptions about dishonest adverts, the constructed environmental risks in the adverts have now become real risks such as the smog that can be smelt or breathed in. Facing such pervasive risk which almost has to be dealt with on a daily basis, parents often expressed the view that there was little they could do but to confine their children to their homes. Such powerlessness is a classic reaction to modern risks - individuals are powerless as they face invisible risks as air pollution, radiological hazards and food contamination which cannot be eradicated and may even be exacerbated by scientific progress (Beck 1992). Other mothers with more resources mentioned that they took children for mountain holiday excursions to avoid air pollutions in the city, or other possible measures to minimise their children's exposure to polluted environment:

E: Our residential area has a good environment; lots of vegetation. There is nothing we can do about the big environment but I try to make it better, at least in my little environment.

F: Her (referring to E) villa is surrounded by woods. ${ }^{14}$ The environment is really good. I sometimes take my son to theirs for dinner, and for some fresh air. (laugh)

Researcher: I heard some people use mobile apps to monitor the PM2.5 level.

\footnotetext{
${ }^{14}$ This mother lives in a villa in an exclusive elite property development in Southern Chengdu.
} 
Final submitted peer reviewed manuscript accepted in European Journal of Cultural Studies (2016) by Gong, Qian., University of Leicester.

E: I bought a set of equipment's for home test. The published government data can't be trusted. (mother from upper middle class background)

By choosing to live in a lush woody environment, mother $E$ improves the 'small environment' for her and her family. She also regularly took her children to Qingcheng mountain during holidays. These efforts reflect individual solutions to risk management that require considerable financial resources. Families with less economic means are unlikely to afford frequent get-away holidays or expensive villas surrounded by lush vegetation in urban China. The 'possibilities and abilities to deal with risks' (Beck, 1992: 35), for example having mountain vacations, are thus unequally divided among parents with different economic backgrounds. The above quotes show that although the (environment) risks are seemingly 'democratic' - that everyone breathes in air pollutants, their management determined by economic positions is far from being equal.

\section{Environmental risks, malnutrition and scientific protection}

When many young children are confined at home because of the (alleged) environmental pollution, adverts for some children's healthcare products conveniently suggest potential health risks for home-bound children. To eliminate these risks, parents have frequent post-natal health checks for their children at hospitals, screening them for allaying nutritional deficiencies. These health checks include monthly examination for weight, length, and head circumference from birth and tri-monthly blood test from six months. ${ }^{15}$ The medical surveillance gives parents 'peace of mind', as explained by a mother. Medical monitoring has become a coping strategy for many parents to manage their children's health problems including malnutrition. Following the discussion of hospital health checks, some parents reported that these health checks often indicated micronutrient deficiency for their children, which was believed to be linked to a lack of exposure to sunlight. Companies such as Dyne Pharma offer Vitamin A and D supplement for babies' calcium deficiency. In the advert, its products, Yikexin vitamin A and D suspensions for babies under one year old, are arranged in the shape of a heart which surround a mother who supports her baby. The clean, off-white background is contrasted with the softly-coloured (pink and green) heart shape made of bottles of the Vitamin supplement. Such composition foregrounds and highlights the central visual elements - a baby supported/loved by his mother, both of whom are surrounded by the Vitamin bottles. It draws on cultural assumptions about mothers - love, care and protection - to suggest that the use of the product manifests mother's love, further signalled through the symbol of heart (see Figure 6).

Figure 6

For many parents who keep their children home because of the perceived environmental risks, this product provide them with a solution and is well received. One mother said:

It's cold outside and the air is acidy in winter. She (the baby) barely goes out and she gets so little sunlight. The doctor prescribed Vitamin A and D for her.

\footnotetext{
${ }^{15}$ For further discussion of the medicalisation of childcare in China, see authors.
} 
Final submitted peer reviewed manuscript accepted in European Journal of Cultural Studies (2016) by Gong, Qian., University of Leicester.

I think it helped. (mother $\mathrm{G}$ from middle class and above background)

Two mothers from another group discussed:

Researcher: Do you give your children Vitamin A and D supplements? $\mathrm{H}$ : I do, mostly in spring, autumn and winter. I don't give them to my kids in summer when they have a lot of outdoor activities.

I: I asked my doctor friend. She told me to do it flexibly. If my son gets plenty of sun exposure, then there is no need to add that. Most mothers I know do it the same way. You can't listen to the ad blindly because it tells you to add the supplement all year round. Actually too much Vitamin A is bad for your health. (mother from middle class background)

While environmental risks are hard to be eliminated by science and modern technology (Beck, 1992), pharmaceutical companies like Dyne are quick to offer remedies. In this case, micronutrients are advertised for facilitating healthy development, which seems befitting with parents' concerns about malnutrition. As discussed previously, many children were home-bound because of the alarming messages of environmental risks conveyed by adverts, news, internet and phone apps. Adverts for micronutrient supplements then offer help for nutritional deficiency caused by home confinement. The micronutrient deficiency, detected by health checks and blood tests, has connected the environmental pollution with malnutrition, transforming perceived risk in the adverts (rain, snow and smoke) into real risks (deficiency supported by medical evidence). These adverts, taken as a whole, skilfully form a coherent, risk-centred narrative of children's healthcare, which further reinforces parents' perceptions about risk and protection.

Other healthcare products that offer solutions to the problem of malnutrition include infant formula, probiotics drinks, fish oil and so on. Some of these products have overlapping functions and ingredients, and they share a common feature - scientific underpinning of the health benefits claimed. However, the scientific evidence for the health benefits is often controversial, which causes a great amount of confusion among parents. In the discussion of adverts for infant formula and fish oils both claiming supplementing micronutrients of DHA and ARA, two fatty acids allegedly having health benefits for brain and eye development, some parents said their practices were based on the idea of 'the more the better' for nutritional supplements, whereas others doubted the idea, believing oversupplementing can be counterproductive. A mother who supported the idea of supplementing more DHA said the recommended daily intake of DHA for her 2-year old son was $160 \mathrm{mg}$, and Mead Johnson infant formula could only provide $70 \mathrm{mg}$ per day, which fell short of the recommendation. When asked where she obtained these figures, she said from the website where the fish oil was sold.

In the United States, the recommended daily intake for DHA for adults is approximately $100 \mathrm{mg}$ (Kris-Etherton et al., 2009). China recently published its recommendation for DHA intake (appro.100mg per day) for infants under 6 months (Xinhua, 2013). European Food Safety Authority recommended 20-50 mg per day for infants 0-6 months of age (Stevens, 2010). All of these figures are less than the figure recognised by the mother. A possible explanation to these differing figures is uncertainties in nutritional science based which 
Final submitted peer reviewed manuscript accepted in European Journal of Cultural Studies (2016) by Gong, Qian., University of Leicester.

recommendations are made. It is argued that risks are complex (Beck, 1992) and that uncertainty is a 'fundamental modern experience' (Zinn, 2006: 277). Parents need expert opinion to understand risks of malnutrition, but experts' assistance can be ambivalent because they may provide conflicting information. The conflicting information provides an opportunity for children's healthcare industry to select the most suitable expert opinion that can maximise their profit on the one hand, and renders new parents even more uncertain about their childcare practices on the other. Faced with the uncertainties in modern scientific knowledge, some parents resorted to traditional and lay nutritional knowledge that operated outside of the dominant Western biotechnological model to manage the health problem of their children. Parents talked about the recent revival of Chinese herbal medicine as an alternative form of knowledge in children's healthcare. Here science often represented as 'foreign, modern medicine' has been extended to traditional Chinese herbal medicine (authors), and both forms of knowledge are being used to protect young children from health risks.

For instance, many parents told me in the focus groups that infant formula had a 'heat property' which caused dry mouth and constipation for their children. Healthcare products such as Meiban are thus advertised to treat the problems caused by infant formula. Meiban cooling granules is a dietary supplement specially designed for removing the heat property, using traditional Chinese herbal remedy including hawkthorn, chrysanthemum, and seed pod of the lotus. These herbal ingredients displayed in an aqua gel wheel (see Figure 7) give visual comfort to the toddler who suffers from constipation. According to traditional Chinese medicine, constipation is usually associated with excessive bodily 'heat' ('shanghuo') which is represented by a red cartoon devil in the advert (Figure 8). The colour codes used here, aqua for 'cool' and red for 'heat', visually represent the function of the granules and the irritating symptom, suggesting that by mixing the 'cool' and 'heat' together, the toddler will achieve a balance for his body.

Figure 7

Figure 8

The above representations in the advert draw on parents' knowledge of Chinese traditional medicine according to which medicinal foods and herbal drinks are thought to regulate various biological functions and bodily organs, nurturing human vitality (Liu, 2004). 'Cool' and 'heat' property of various foods and drinks were well known to the parents. Focus group discussions revealed that constipation for formula-fed children was common. Although this advert did not mention infant formula for causing constipation, many participants voluntarily linked them together, believing constipation was some kind of 'side effect' of formula-feeding. Another aspect of the advert - treatment needed - was well accepted by the parents, as many of them self-diagnosed their children with excessive bodily heat. While some parents reported that they had bought and tried this brand or other similar products before, many others told me that they 'treated' the constipation themselves, using other medicinal food such as bananas, moong beans and cucumbers, which was guided by their cultural knowledge of medicinal foods. These discussions show that parents draw on their cultural repertoire and existing knowledge to interpret information from the advert. They actively use their own experience and knowledge to explore other natural, and perhaps less expensive ingredients to help alleviate the symptoms for their children. A positive interpretation of these practices is that parents act 
Final submitted peer reviewed manuscript accepted in European Journal of Cultural Studies (2016) by Gong, Qian., University of Leicester.

as agenic beings who critically reflect on the Western scientific knowledge, contesting the dominant medicalised practices. However, no one questioned the use of infant formula which had caused such 'side effect' in the first place, or the alleged health benefits of infant formula. ${ }^{16}$ Meanwhile pharmaceutical companies like Meiban offer products to treat the 'side-effect' of formula-feeding - constipation that should probably not have existed if babies were breastfed. As parents accept the message of this advert that their children need more cooling property to balance the heat caused by formula-feeding, infant formula companies and pharmaceutical companies reap commercial benefits from their interconnected healthcare products. ${ }^{17}$

\section{Conclusion}

This paper has analysed the representation and reception of the advertising of children's healthcare products as a lens to understand the modern cultural experience of risk in China. TV adverts of these products have constructed a coherent narrative about young children's health-related risks, comprising messages of environment, nature, nutrition, science, and protection. Within the narrative, interconnected risks - risks of everyday living, risks of environment pollution, risk of malnutrition - as well as a wider discourse of 'risk and protection' are constructed. Natural and everyday living environments are constructed as potentially dangerous in the adverts through a range of verbal and visual signifiers. Verbal words in voice-overs (e.g. damage, pollution, protection, assured) are used to explicitly suggest risk and danger or inexplicitly imply them. The message of danger and risk is often accompanied by visual images including shield, umbrella, gloves, kangaroo pouch, angel's wrapping wings and mother, all of which serve as explicit signifiers of 'protection'. ${ }^{18}$

Many parents are receptive of the message of 'protection' as they voluntarily link the environment risks (sometimes benignly) represented in the adverts to the environmental pollution that has sustained negative coverage in various media in China in recent years. To make sense of the message 'dangerous nature requiring protection' signalled by favourable images (blue sky, green pasture), parents draw on their 'interpretive codes' formed by both 'perceptual' and 'ideological' codes (Chandler, 2007: 150). Parents' perceptions based on personal experiences (hospitalised child, blood test), pre-existing knowledge (home test results for pollution) and beliefs (dishonest adverts) as well as their knowledge systems and cultural beliefs influenced by neoliberalism and individualisation (neoliberal healthcare and self-care) shape the ways in which they make sense of the messages in the adverts, leading them to accept certain meanings (risk and protection) but reject others (pristine natural environments exist in China). Parents' selective reception of the meanings shows the complex ways in which the media can (or cannot) have influence

\footnotetext{
${ }^{16}$ For related debates about infant feeding and its wider socioeconomic and political context, see authors.

${ }^{17}$ Children's healthcare products are sold at distortedly high prices for their alleged premium nutritional value. Mid-market infant formula products (800 gram) from international brands (e.g. Abbott) cost between $¥ 200$ 300 (US\$ 35-50).

${ }^{18}$ An underlying assumption in all these representations is that children are innocent, cherished and wondrous but simultaneously fragile, vulnerable and in need of extra protection. This assumption has received little challenge in this study even though a growiftg body of literature researching children's own experiences and understandings of health issues suggests that they sometimes act as active agents (See for example Brady, et al. 2015; Mayall, 2015).
} 
Final submitted peer reviewed manuscript accepted in European Journal of Cultural Studies (2016) by Gong, Qian., University of Leicester.

on their perceptions - it appears media influence only takes place when the meanings conveyed are congruent with people's wider values, knowledge, views, and interests, as observed by Lewis and Lewis (2015: 33).

For some parents, the positive reception of the message of 'protection' is also shaped by emotive feelings such as fear and dread (of baby's suffering), uncertainty and anxiety caused by a lack of trust of the authorities and of confidence of own parenting knowledge. Everyday encounters with newspapers, advertising, mobile apps and the internet consolidate these emotive feelings and provide parents with important sources of information for rational assessment. This supports Lewis and Lewis' (2015) claim about the central role of the media in communicating messages and meanings about health. Parents take individual solutions to mitigate the consequences of the risks which usually require considerable personal financial resources. The 'possibilities and abilities to deal with risks' (Beck, 1992: 35) are therefore unequally mapped onto the economic hierarchy on which families are situated. The protective measures that many parents take - confine their children at home - have given rise to concerns about vitamin A and D deficiency for lacking exposure to sunlight, which provides a new ground for the healthcare product industry to claim risks of malnutrition. Parents are again susceptible to such claim as postnatal health checks and blood tests often confirm micronutrient deficiencies. Such experience connects the environmental pollution with malnutrition, transforming the perceived risk of environment pollution (signified by rain, snow, industrial chimney and smoke) into real risks of nutritional deficiency (supported by medical test results).

In hopes of managing these health risks, protection based on scientific knowledge has been offered as a key solution. However complexities and controversies in expert knowledge are exploited by commercial interests for maximising profit but simultaneously invoking more fear and uncertainty among parents. The uncertainty deriving from the complex nature of biomedical science has prompted some parents to resort to traditional Chinese herbal medicine as an alternative form of scientific knowledge that operates outside of the dominant Western medical practices. Lay knowledge of medicinal food, usually passed down from grandparents, enables parents to creatively interpret advertising messages (images of the ingredients of Meiban cooling granules), and prompt them to explore other natural and less expensive ingredients to manage health problems such as constipation. By resisting some medicalised and commercialised hegemonic practices, parents are engaged in the meaning-making process and becoming 'agents of change' (Lewis and Lewis, 2015: 13). While these practices demonstrate the reflexivity and agency of some parents who are able to contest the dominant discourses, others parents tend to conform to the hegemonic discourse of medicalisations and commercialisation, raising little challenge to the alleged benefits of the advertised products. The different responses among parents show that risk experiences are highly contextual and individual, not only in the ways that the meanings of risks are perceived, but also in the ways that they are managed. Multiple meanings about how to manage health risks - with expert-directed biomedicine or lay knowledge of medicinal food - can be generated as people interpret media texts differently based on past experiences, pre-existing knowledge in their lived everyday context (Lewis and Lewis, 2015: 13). 
Final submitted peer reviewed manuscript accepted in European Journal of Cultural Studies (2016) by Gong, Qian., University of Leicester.

within a neoliberal, commodified and medicalised childcare environment which emphasises self-care and individual responsibilities. Yet the responsibilities of eliminating risks largely fall on parents whose ontological and economic security has been increasingly eroded by rising costs of children's healthcare and basic living needs, a result of the withdrawal of state support in the health sector and the under-regulated healthcare industry in China. ${ }^{19}$ Parents' experiences of risk are localised in the social, economic, historical and political contexts in China. For instance parents' background knowledge of heavy environmental pollution in China evidently facilitated establishing the links between 'environment', 'danger' and 'protection'. Chinese parents' vulnerability to commercial exploitation based on risk construction as well as their wider anxieties about childrearing are situated within a context of rising costs for childrearing, increasing medicalisation, expensive medical bills, and inadequate government guidance of and regulation of the healthcare market. All of these together with a general lack of experience with young children due to China's one-child policy significantly erode parental confidence. ${ }^{20}$ While many of these issues are sociallycaused, parents speak little of public-oriented, collective actions or initiatives to change the status quo in the healthcare system, state regulation or consumer right protection. Their little trust of the public institutions creates a vacuum for under-regulated commercial interests to play a prominent role in the public life. This too is consistent with the historical development of the state-sponsored individualisation process in China, in that the establishment of basic civic, political and social rights such as freedom of speech and assembly has been 'truncated' (Beck and Beck-Gernsheim, 2010; Yan, 2010). Therefore the management of children's health risks remains largely individual, isolated and unsupported, which in turn is likely to reinforce the risk-centred narrative in the uncertain cultural experience of parenting in China. The above accounts show that the representation and reception of the risk discourse cannot be isolated from its social, cultural and historical contexts (Lupton, 1999, p.2), and that the risk-centred cultural experience of parenting in China is 'inevitably the outcome' of the above sociocultural processes.

\section{Bibliography}

Ang I. (1996) Living Room Wars: Rethinking Media Audiences for a Postmodern World, London: Routledge.

Authors.

Barker C. (2012) Cultural Studies: Theory and Practice, London, Thousand Oaks, New Delhi, Singapore: Sage.

Beck-Gernsheim E. (2000) Health and Responsibility: From Social Change to Technological Change and Vice Versa. In: Adam B, Beck U and Van Loon J (eds) The Risk Society and Beyond: Critical Issues for Social Theory. 122-135.

Beck U. (1992) Risk Society: Towards a New Modernity, London: Sage Publications.

Beck U and Beck-Gernsheim E. (1995) The Normal Chaos of Love, Cambridge and Oxford: Polity Press.

\footnotetext{
${ }^{19}$ For the discussion of lax government regulation of children's healthcare product market, see authors. With added cost of nappies, low-middle income families with a baby feeding exclusively on formula milk spend around $¥ 2,000$ (US\$300) per month on basic living needs which accounts for between one third and half of the total family monthly income.

${ }^{20}$ Based on recent German experience, Beck and Beck-Géphsheim argue (1995: 130) young adults' first close encounter with an infant is probably their own first child. The lack of experience is also true for young adults in China because they encounter fewer children as they grew up with no or few siblings.
} 
Final submitted peer reviewed manuscript accepted in European Journal of Cultural Studies (2016) by Gong, Qian., University of Leicester.

Beck U and Beck-Gernsheim E. (2010) Varieties of Individualization. In: Hansen MH and Svarverud R (eds) iChina: The Rise of the Individual in Modern Chinese Society. Copenhagen: NIAS Press, xiii-xx.

Berger A. (2012) Media Analysis Techniques, Los Angeles and London: Sage.

Chandler D. (2007) Semiotics: the basics, London and New York: Routledge.

Chen N. (2008) Consuming Medicine and Biotechnology in China. In: Zhang L and Ong A (eds) Privatizing China: Socialism from Afar. Ithaca and London: Cornell University Press, 123-132.

Chen NC. (2001) Health, Wealth and the Good Life. In: Chen NN, Clark C, C. and Gottschang SZ (eds) China Urban: Ethnographies of Contemporary Culture. 165-182.

Daemmrich A. (2013) The political economy of healthcare reform in China: negotiating public and private. Springerplus 2.

Davis D. (2000) The consumer revolution in urban China. Berkeley, Calif. ; London University of California Press.

Du J. (2009) Economic reforms and medical insurance in China. Social Science and Medicine 69: 387395.

Euromonitor. (2015) Vitamins and Dietary Supplements in China. Available at: http://www.euromonitor.com/vitamins-and-dietary-supplements-in-china/report.

Griffiths MB. (2013) Consumers and individuals in China: standing out, fitting in, London and New York: Routledge.

Hall S. (1997) Representation: Cultural Representations and Signifying Practices, London: Sage.

Hong J. (1994) The resurrection of advertising in China: Developments, problems, and trends. Asian Survey 34: 326-342.

Huang S, Du G and Shao H. (2010) A study of the current state and furture trend of the marketing of healthcare and food industry (2009-2010). In: Huang S, Du G and Shao H (eds) Report on the Promotion Trend of China's Advertisers. Beijing: Social Sciences Academic Press, 201-233.

Klein J. (2013) Everyday Approaches to Food Safety in Kunming. China Quarterly: 376-393.

Knaak SJ. (2010) Contextualising risk, constructing choice: Breastfeeding and good mothering in risk society. Health Risk \& Society 12: 345-355.

Kohrman M. (2008) Should I Quit? Tobacco, Fraught Identity, and the Risks of Governmentality. In: Zhang L and Ong A (eds) Privatizing China: Socialism from Afar. Ithaca and London: Cornell University Press, 133-150.

Kris-Etherton P, Grieger J and Etherton T. (2009) Dietary reference intake for DHA and EPA. Available at: http://www.ncbi.nlm.nih.gov/pubmed/19525100.

Lash S. (1993) Reflexive Modernization: The Aesthetic Dimension. Theory, Culture \& Society 10: 1-23.

Lee E. (2008) Living with risk in the era of 'intensive motherhood': Maternal identity and infant feeding. Health, risk and society 10: 467-477.

Lewis B and Lewis J. (2015) Health Communication: A Media \& Cultural Studies Approach, London and New York: Palgrave.

Lewis T, Martin F and Sun W. (2012) Lifestyling Asia? Shaping modernity and selfhood on life-advice programming. International Journal of Cultural Studies 15: 537-566.

Li L. (2011) The challenges of healthcare reforms in China. Public Health 125: 6-8.

Liu X. (2004) Han. In: Ember CR and Melvin E (eds) Encyclopaedia of Medical Anthropology: Health and IIIness in World's Cultures. New York Kluwer Academic/Plenum Publishers, 703-717.

Liu X and Mills A. (2002) Financing reforms of public health service in China: Lessons for other nations. Social Science and Medicine 54: 1691-1698.

Lupton D. (1999a) Introduction: risk and sociocultural theory In: Lupton D (ed) Risk and sociocultural theory: New Directions and Perspectives. Cambridge: Cambridge University Press, 1-11.

Lupton D. (1999b) Risk and the ontology of pregnant embodiment In: Lupton D (ed) Risk and sociocultural theory: New Directions and Perspectives. Cambridge: Cambridge University Press, 59-85.

Lupton D and Tulloch J. (2002) 'Risk is part of your life': Risk epistemologies among a group of 
Final submitted peer reviewed manuscript accepted in European Journal of Cultural Studies (2016) by Gong, Qian., University of Leicester.

Australians. Sociology-the Journal of the British Sociological Association 36: 317-334.

Manning N. (2011) The Reform of Health Policy in China - Left Behind in the Race to Industrialize? Social Policy \& Administration 45: 649-661.

Morley D. (1980) The Nationwide Audience, London: British Film Institute.

Morley D. (1992) Television, Audiences and Cultural Studies, London: Routledge.

Murphy E. (2000) Riks, Responsibility and Rhetoric in Infant Feeding. Journal of Contemporary Ethnography 29: 291-325.

Saussure F. (1983) Course in general linguistics, London: Duckworth.

Silverstone R and Hirsch E. (1992) Consuming Technologies: Media and Information in Domestic Spaces. London: Routledge.

Stevens H. (2010) International Formula Council (IFC) Statement on DHA/ARA and Infant Formula. Available at: http://www.infantformula.org/news-room/press-releases-andstatements/infant-formula-and-dha/ara.

Sun W. (2015) Cultivating self-health subjects: Yangsheng and biocitizenship in urban China. Citizenship Studies 19: 285-298.

Thiers P. (2003) Risk Society Comes to China: SARS, Transparency and Public Accountablity. Asian Perspective 27: 241-251.

United States Environmental Protection Agency. (2014) What is PM2.5? Available at: http://www.epa.gov/pmdesignations/faq.htm\#0.

Wilkinson I. (2001) Anxiety in a Risk Society London and New York: Routledge.

Xinhua. (2013) The publication of infants and young children's DHA and Choline Dietary reference intakes. Available at: http://news.xinhuanet.com/health/2013-05/21/c 124742015.htm.

Yan Y. (2010) The Chinese path to individualization. British Journal of Sociology 61: 489-512.

Zinn J. (2006) Recent developments in sociology of risk and uncertainty. Historical Social ResearchHistorische Sozialforschung 31: 275-286.

Zinn JO. (2008) Heading into the unknown: Everyday strategies for managing risk and uncertainty. Health Risk \& Society 10: 439-450. 